107 Royal Netherlands Institute for Sea Research

This is a postprint version of:

Lengger, S. K., Hopmans, E. C., Sinninghe Damsté, J. S., \& Schouten, S. (2012). Comparison of extraction and work up techniques for analysis of core and intact polar tetraether lipids from sedimentary environments. Organic Geochemistry, 47, 34-40.

Published version: http://dx.doi.org/10.1016/j.orggeochem.2012.02.009

Link NIOZ Repository: $\underline{w w w . v l i z . b e / n l / i m i s ? m o d u l e=r e f \& r e f i d=231069}$

[Article begins on next page]

The NIOZ Repository gives free access to the digital collection of the work of the Royal Netherlands Institute for Sea Research. This archive is managed according to the principles of the Open Access Movement, and the Open Archive Initiative. Each publication should be cited to its original source - please use the reference as presented.

When using parts of, or whole publications in your own work, permission from the author(s) or copyright holder(s) is always needed. 


\title{
COMPARISON OF EXTRACTION AND WORK UP TECHNIQUES FOR ANALYSIS OF CORE AND INTACT POLAR TETRAETHER LIPIDS FROM SEDIMENTARY ENVIRONMENTS
}

\author{
Sabine K. Lengger, Ellen C. Hopmans, Jaap S. Sinninghe Damsté, Stefan Schouten \\ Department of Marine Organic Biogeochemistry, Royal NIOZ Netherlands Institute for Sea Research, P. \\ O. Box 59, 1790AB Den Burg, Texel, The Netherlands.
}

as published in: Organic Geochemistry 47 (2012), 34 - 40

http://dx.doi.org/10.1016/j.orggeochem.2012.02.009

\begin{abstract}
Glycerol dibiphytanyl glycerol tetraether-based intact polar lipids (IPL-GDGTs) are used as biomarkers for living Archaea and are analyzed utilizing a variety of extraction and quantification techniques. Most IPLGDGT studies have used a modified Bligh-Dyer extraction method, but it has been suggested that soxhlet extraction may be more efficient for IPL-GDGT extraction from environmental samples and biomass. We investigated the impact of three different extractions (soxhlet, Bligh-Dyer and accelerated solvent extraction, ASE), two IPL quantification methods and two work up techniques $\left(\mathrm{Na}_{2} \mathrm{SO}_{4}\right.$ and $\mathrm{SiO}_{2}$ column) on the amount and distribution of CL- and IPL-derived GDGTs and crenarchaeol-based IPLs in marine sediments from the Arabian Sea and Icelandic shelf and a microbial mat from a Dutch beach. The different extraction procedures gave a similar yield of CL- and IPL-derived GDGTs. Direct analysis of crenarchaeol IPLs showed, however, that, while GDGTs with a monohexose headgroup were not affected by the extraction method, there was a large effect on IPL-GDGTs containing dihexose or hexose, phosphohexose head groups. Quantification of IPL-derived GDGTs by way of either separation over a silica column or by subtraction of CLGDGTs in the total lipid extract before and after hydrolysis gave similar results, but the 'subtraction-method' had a relatively large quantification error. However, the silica column, as well as drying over a $\mathrm{Na}_{2} \mathrm{SO}_{4}$ column, resulted in a loss of the hexose, phosphohexose IPLs by up to $80 \%$. Based on the results, a modified Bligh-Dyer extraction with as little further treatment as possible is recommended to allow measurement of the full range of IPLGDGTs in sediments.
\end{abstract}


Members of the domain of Archaea occur in many extreme and moderate environments (Schleper, 2007 and references therein). Their cell membranes consist of distinctive ether lipids, amongst which glycerol dibiphytanyl glycerol tetraether (GDGT) lipids are common (Fig. 1; de Rosa and Gambacorta, 1988; Sinninghe Damsté et al., 2002b). In the marine environment, the most abundant Archaea are the mesophilic Marine Group I Crenarchaeota (DeLong, 1992; Fuhrman et al., 1992; DeLong et al., 1998; Karner et al., 2001; Schouten et al., 2002), which have been recently proposed to form a separate phylum called Thaumarchaeota, together with other related, ammonia-oxidizing Crenarchaeota (Brochier-Armanet et al., 2008; Spang et al., 2010). These are also the only known producers of crenarchaeol (Sinninghe Damsté et al., 2002b; Schouten et al., 2008; Pitcher et al., 2010), the most abundant GDGT in the marine environment (Schouten et al.,

a
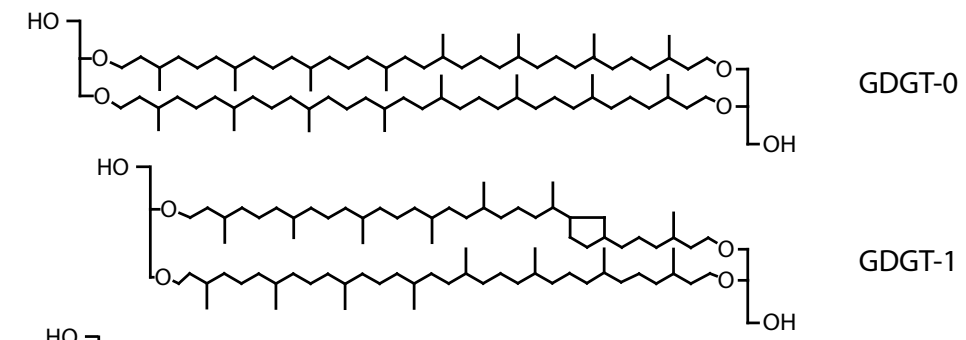

GDGT-1

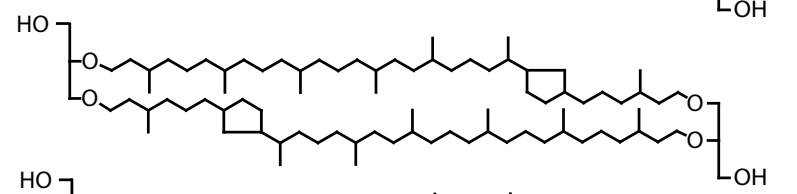

GDGT-2

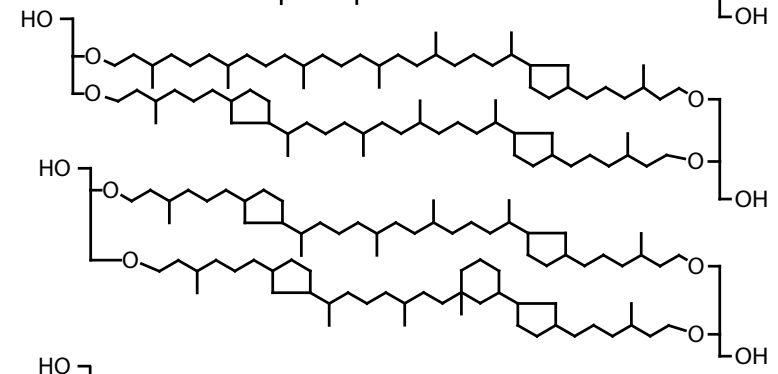

GDGT-3

Crenarchaeol

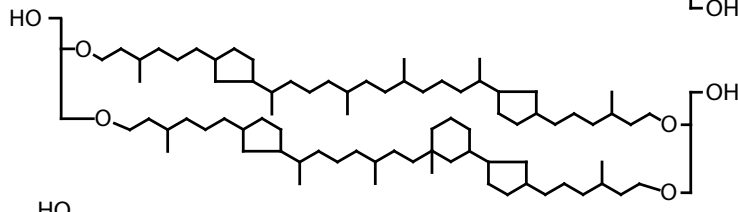

Crenarchaeol isomer

b

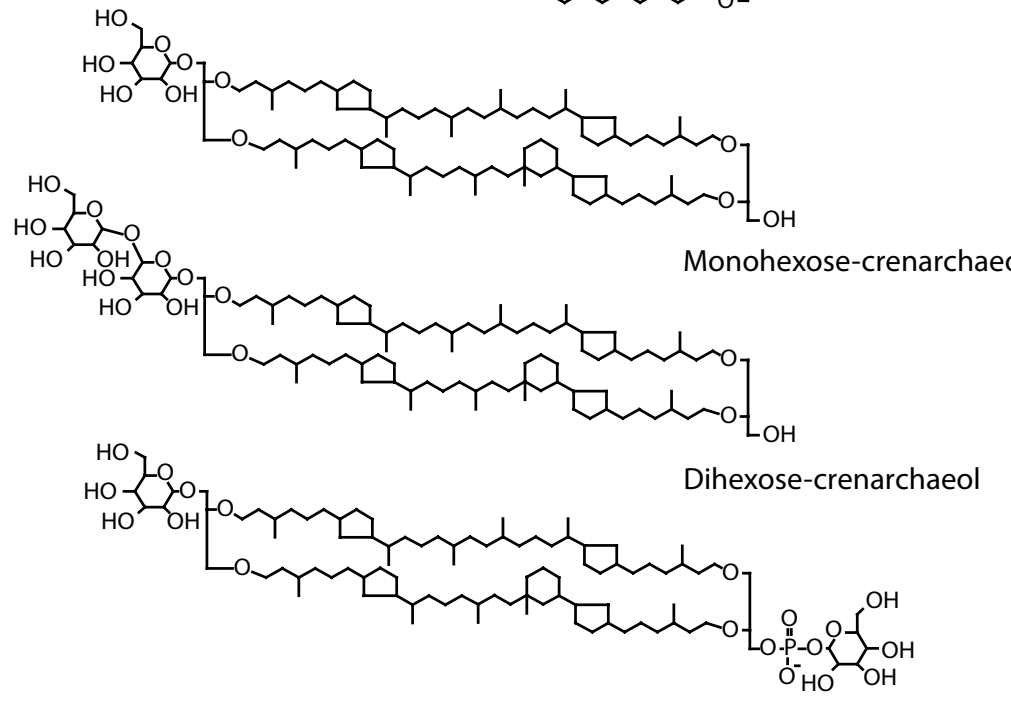

Hexose, phosphohexose-crenarchaeol

Figure 1. Structures of CL-GDGTs (a) and IPLs with crenarchaeol as a core lipids (b) analyzed in this study. 
2000). In intact cells, GDGTs occur with polar head groups (intact polar lipids, IPLs; e.g. Fig. 1; Koga et al., 1993; Macalady et al., 2004; Koga and Morii, 2005; Schouten et al., 2008; Pitcher et al., 2010), which have been proposed to be rapidly lost after cell death to afford the more stable core lipids (CLs; White et al., 1979; White and Ringelberg, 1998). Hence, analysis of IPL-GDGTs from the environment can, just as for phospholipid-derived fatty acids for bacteria and eukaryotes (cf. White et al., 1979; Boetius and Lochte, 2000), potentially give valuable information about the occurrence of living Archaea (Sturt et al., 2004; Biddle et al., 2006; Pitcher et al., 2011b). However, it has also been suggested that archaeal etherlipids do not degrade as rapidly as bacterial lipids (Harvey et al., 1986; Schouten et al., 2010; Logemann et al., 2011).

Several techniques are available for extracting IPLs and distinguishing them from their fossil counterparts, the CLs. Extraction usually follows a procedure modified from Bligh and Dyer (1959). Following extraction, IPLs can be isolated using separation techniques varying from preparative high performance liquid chromatography (HPLC; Biddle et al., 2006; Schubotz et al., 2009) to $\mathrm{SiO}_{2}$ column chromatography (Oba et al., 2006; Pitcher et al., 2009b; Liu et al., 2011) or directly analyzed (Lipp et al., 2008; Pitcher et al., 2011b). CL-GDGTs can be quantified using HPLC-atmospheric pressure chemical ionization-mass spectrometry (HPLC-APCIMS), but IPL-GDGTs with their polar labile head groups have to be analyzed using other techniques such as HPLC-electrospray ionization-tandem mass spectrometry (HPLC-ESI-MS ${ }^{2}$;Sturt et al., 2004). Unfortunately, pure IPL-GDGT standards identical to those found in the natural environment are not commercially available, thereby hindering exact quantification of IPL-GDGTs as ionization efficiency can vary significantly between IPLs (Zink et al., 2003; van Mooy et al., 2009) . Indirect quantification of total IPL-GDGTs is, however, possible after separation from CL-GDGTs and subsequent cleavage of the head groups using acid hydrolysis, which converts them to the quantifiable IPL-derived GDGTs (Pitcher et al., 2009b).

Virtually all studies examining IPL-GDGTs in biomass, sediment, soil and water samples have used a modified Bligh-Dyer technique for extraction. (e.g. Biddle et al., 2006; Schouten et al., 2008; Schubotz et al., 2009; Pitcher et al., 2011b). However, only a few studies have quantitatively examined the effect of extraction and work up on IPL-GDGTs. In fact, Huguet et al. (2010a) have recently suggested that Bligh-Dyer extraction, most commonly used for eukaryotic and bacterial IPLs (White et al., 1996), may be less suitable for extraction of archaeal IPLGDGTs and instead Soxhlet extraction may be preferred. In addition, it was suggested that the concentration of IPL-GDGTs can be determined by determining the concentration of GDGTs in the total lipid extract before and after acid hydrolysis using the so-called 'subtraction' method. In this method, the concentration before hydrolysis represents the CL-GDGTs and the concentration after hydrolysis the IPL-derived plus CL-GDGTs. By subtraction of the latter concentration from that of the former, the concentration of IPL-derived GDGTs can be obtained.

To further investigate the efficiency of these extraction techniques, we compared Soxhlet and Bligh-Dyer techniques in quantification of CL- and IPL-derived GDGTs in sediments from the Arabian Sea and Iceland continental shelf, as well as a microbial mat from a Dutch beach. We compared this with accelerated solvent extraction (ASE), a common technique for extract ingCL-GDGTs but not IPL-GDGTs, as it is assumed to destroy part of the IPLs (cf. Huguet et al., 2010a). However, it has been reported that ASE at $100{ }^{\circ} \mathrm{C}$ and 20 $\mathrm{kPa}$ is capable of quantitatively extracting glycolipids from heterocystous cyanobacteria (Bauersachs et al., 2010), so we re-investigated its potential for extracting archaeal IPLs. IPL quantification was carried out by way of separation over $\mathrm{SiO}_{2}$, followed by acid hydrolysis, according to Pitcher et al. (2009b), and by direct hydrolysis according to Huguet et al. (2010a). We also directly measured IPL-crenarchaeol using HPLC-ESI$\mathrm{MS}^{2}$ in order to compare the extraction efficiency of the methods for different headgroups. Finally, two commonly used work up procedures, i.e. $\mathrm{SiO}_{2}$ column chromatography and drying over $\mathrm{Na}_{2} \mathrm{SO}_{4}$ and their effect on IPL distribution were investigated via direct measurement of IPL-crenarchaeol. 


\subsection{Materials}

We used two sediments and one microbial mat sediment. One sample consisted of a large freeze-dried and homogenized composite sample from core top sediments from various water depths (900-3000 m) collected from the Murray Ridge in the Arabian Sea in January 2009. A second sample was a composite sample produced from core tops collected south east and north east off the Iceland shelf in July 2011 at 240-262 m water depth. Finally, a homogenized microbial mat sediment from Green beach at Schiermonnikoog, NL, collected in June 2009 was used. The mat was a mature, as described by Bolhuis and Stal (2011), who analyzed microbial diversity in a similar mat (ST3) and found an archaeal community composed mainly of Halobacteria, but also Marine Group I Crenarchaeota. All samples were frozen immediately after collection.

\subsection{Sediment extraction and analysis of GDGTs}

Three extraction procedures were used: a modified Bligh-Dyer procedure (Bligh and Dyer, 1959) as described by White and Ringelberg (1998), ASE as described by Huguet et al. (2006) and Soxhlet extraction according to Huguet et al. (2010a). All extractions were performed in triplicate. One blank extraction with $2.0 \mathrm{~g}$ diatomaceous earth was used, was performed for each extraction technique. For each experiment $2.0 \mathrm{~g}$ of Arabian Sea sediment and Iceland sediment and $3.0 \mathrm{~g}$ of the microbial mat were used.

For Bligh-Dyer extraction, samples were extracted $\mathrm{x} 3$ using ultrasonication in dichloromethane (DCM)/ $\mathrm{MeOH} / 0.1 \mathrm{M}$ phosphate buffer (PB; 2:1:0.8 v:v) at $\mathrm{pH}$ 7.4and the solvent collected after centrifugation. The combined liquid phase was adjusted to a solvent ratio of DCM/MeOH/PB 1:1:0.9 v:v and centrifuged to achieve phase separation and the DCM phase was collected. The extraction was repeated twice with fresh DCM and all DCM phases were combined. For ASE extraction, the samples were extracted after addition of pre-extracted diatomaceous earth in an Accelerated Solvent Extractor 200 (ASE 200, DIONEX, CA, USA) with a mixture of DCM/MeOH 9:1 v:v at $100^{\circ} \mathrm{C}$ and $7.6 \times 10^{6} \mathrm{~Pa}$. For Soxhlet extraction, the samples were placed in pre-extracted thimbles and extracted in Soxhlet extractors in a water bath at $60{ }^{\circ} \mathrm{C}$ using $50 \mathrm{ml}$ $\mathrm{DCM} / \mathrm{MeOH}$ 9:1 (v/v) for $72 \mathrm{~h}$.

From all extracts, the solvent was removed using a rotary evaporator and the extract redissolved in DCM/ $\mathrm{MeOH}$ 9:1 (v/v), filtered over a $1 \mathrm{~cm}$ plug of cotton wool in a Pasteur pipette and dried using a stream of $\mathrm{N}_{2}$. The extracts were stored at $-20{ }^{\circ} \mathrm{C}$ until analysis. Each extract was dissolved in DCM/MeOH9:1 (v/v) and divided into aliquots.

One (30\%) was fractionated over a $\mathrm{SiO}_{2}$ column in order to separate IPL-GDGTs from CLGDGTs, following the procedure of Oba et al. (2006) and Pitcher et al. (2009b) with some modification: the CL fraction was eluted with $6 \mathrm{ml}$ hexane/EtOAc 1:2 (v/v) and the IPL fraction with $10 \mathrm{ml} \mathrm{MeOH}$. To each fraction, $0.1 \mu \mathrm{g}$ of an internal $\mathrm{C}_{46}$ glycerol trialkyl glycerol tetraether (GTGT) standard (Huguet et al., 2006) was added. The IPL fraction was hydrolyzed for $3 \mathrm{~h}$ under reflux in $2 \mathrm{~N}$ methanolic $\mathrm{HCl}$ to release the IPL-derived GDGTs (Pitcher et al., 2009b). Another aliquot of $30 \%$ was analyzed by way of a 'subtraction technique' as described by Huguet et al. (2010). It was divided into two equal parts. Each was spiked with $0.1 \mu \mathrm{g}$ internal $\mathrm{C}_{46} \mathrm{GTGT}$ standard. One part was separated on an $\mathrm{Al}_{2} \mathrm{O}_{3}$ column using $3 \mathrm{ml}$ hexane/DCM 9:1 (v/v) and $3 \mathrm{ml} \mathrm{DCM} /$ $\mathrm{MeOH} \mathrm{1:1} \mathrm{(v/v)} \mathrm{to} \mathrm{yield} \mathrm{an} \mathrm{apolar} \mathrm{fraction} \mathrm{and} \mathrm{the} \mathrm{CL-GDGT-containing} \mathrm{polar} \mathrm{fraction.} \mathrm{The} \mathrm{other} \mathrm{half} \mathrm{was}$ directly acid hydrolyzed as described above to give the total 'CL+IPL-derived' GDGTs and then separated over $\mathrm{Al}_{2} \mathrm{O}_{3}$ as described above, to yield an apolar and a polar fraction, with the latter containing the total (CL+IPL-derived) GDGTs. After analysis, subtraction of these values afforded the concentration difference 
representing the IPL-derived GDGTs. These two quantification methods were only applied to the Arabian Sea sediment extracts. The third 30\% aliquots of the extracts were directly analyzed using HPLC-ESI-MS ${ }^{2}$ for crenarchaeol-based IPLs. Also, 30\% aliquots of the microbial mat and Iceland shelf sediments were subjected to this direct analysis method.

\subsection{Work up for direct IPL analysis}

To test the procedures for direct analysis of archaeal IPLs, an additional, large, combined Bligh-Dyer extract of similar, but not identical Arabian Sea core top sediment, was obtained and divided into 9 aliquots. Three were not treated, three were eluted over a $\mathrm{Na}_{2} \mathrm{SO}_{4}$ column using DCM/MeOH 9:1 (v/v) and three were subjected to $\mathrm{SiO}_{2}$ column chromatography to obtain an IPL fraction as described in Section 2.2. A composite Bligh-Dyer extract (several combined core top extracts) of the Iceland Shelf sediment was split into six aliquots, three of which were also subjected to $\mathrm{SiO}_{2}$ column chromatography, while three were analyzed directly for IPLs. All these fractions were analyzed for crenarchaeol-based IPLs using HPLC-ESI-MS².

\subsection{HPLC-APCI-MS and HPLC-ESI-MS ${ }^{2}$}

CL- and IPL-derived GDGTs (Fig. 1a) were analyzed using an Agilent 1100 series LC-MSD SL instrument according to Schouten et al. (2007b), using an internal $\mathrm{C}_{46}$ GTGT standard as described by Huguet et al. (2006c).

Crenarchaeol-based IPLs were directly analyzed by way of HPLC-ESI-MS ${ }^{2}$ modified from Sturt et al. (2004) using a Thermo Quantum Ultra EM triple quadrupole mass spectrometer in selected reaction monitoring (SRM) mode (Pitcher et al., 2011b). Crenarchaeol with a monohexose (MH), dihexose (DH) or hexose, phosphohexose (HPH) head group (Fig. 1b) were detected using transitions from $\mathrm{m} / \mathrm{z} 1471$ to $1292, \mathrm{~m} / \mathrm{z}$ 1634 to 1292 , and $m / z 1713$ to 1534 , respectively, with an Ar collision gas pressure of 0.8 mTorr. IPLs were quantified as the integrated IPL peak area response $\mathrm{g}^{-1}$ of sediment dry wt. All samples were analyzed in duplicate. Long term performance of the mass spectrometer was monitored by injecting an aliquot of a core top extract at regular intervals during analytical sessions. Blanks did not show the presence of any IPL-GDGTs or CL-GDGTs for any extraction method. In order to check for possible ion suppression effects due to matrix extracted from either the diatomaceous earth used in ASE or the thimbles used in Soxhlet extraction, BlighDyer extract of the microbial mat and the Iceland sediment were mixed with ASE and Soxhlet blank extracts and analyzed via HPLC/ESI-MS². No ion suppression was observed.

\subsection{Data treatment}

The results were statistically tested via ANOVA if normally distributed and of equal variance; if not, then ANOVA on ranks, where the data underwent a rank transformation before conducting the ANOVA, was used (Sigmastat/Sigmaplot 11.0; Systat Software Inc., 2008). Standard deviations were calculated for the average of the triplicate experiments. For the subtraction method, the standard deviation was calculated from the two measurements according to error propagation laws as the square root of the sum of their variance. Factor analysis (principal components, PCs) in order to test if all GDGTs were affected similarly by the extraction methods was carried out with Systat 13.0 (Systat Software Inc., 2009).

RESULTS AND DISCUSSION

\subsection{Efficiency of extraction for CL- and IPL-derived GDGTs}

We evaluated differences in the efficiency of methods for the extraction of GDGTs from a composite marine sediment from the Arabian Sea. For the extracts, concentration was determined for CL-GDGTs and IPL- 


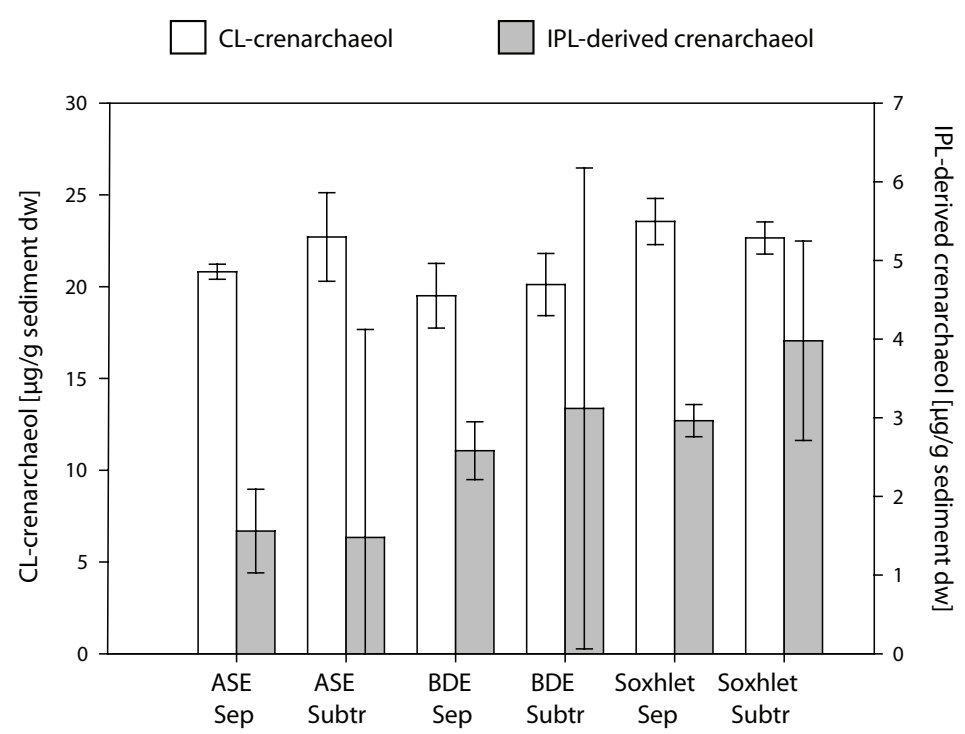

Figure 2. Concentrations of GDGT crenarchaeol ( $\mu \mathrm{g} / \mathrm{g}$ sediment dry weight) as determined from

ASE, Bligh-Dyer and Soxhlet extraction, applying two quantification methods of a composite Arabian Sea Bligh-Dyer extract. Labels 'Sep' and 'Subtr' refer to CL and IPL-derived crenarchaeol measured after separation over silica (Pitcher et al., 2009) and to the 'subtraction method'. Data presented are the means of triplicate extractions and error bars indicate \pm standard deviation.

derived GDGTs using the analytical protocols based on chromatographic separation over $\mathrm{SiO}_{2}$ (Pitcher et al., 2009) and the 'subtraction' method (Huguet et al., 2010). Concentrations of all GDGTs studied (Fig. 1a) were highly correlated with each other. A PC analysis showed that the first component explained $99.8 \%$ of the overall variation and all loadings exceeded 0.99 . This means that all of the variation in GDGT concentration could be explained by the different extraction and quantification methods, he type of GDGT having no effect. Since all GDGTs were affected similarly by the extraction and analysis techniques used, we only show the results for crenarchaeol, but conclusions reached also hold for GDGT-0, -1, -2, -3 and crenarchaeol isomer.

Quantification of CL-crenarchaeol (Fig. 2; white bars) using the three different extraction and two separation methods revealed similar results, with only Soxhlet extraction yield being slightly, but significantly higher than Bligh-Dyer extraction yield. This indicates that all these extraction and separation techniques are suitable for CL-GDGT analysis.

IPL-derived crenarchaeol concentration (Fig. 2; grey bars) showes different patterns vs. the CL-crenarchaeol concentration (Fig. 2a). ASE yield was significantly lower than the Bligh-Dyer and Soxhlet yields for the IPLderived crenarchaeol for the separation method (Fig. 2). This is in agreement with observations by Huguet et al. (2010) and indicates that ASE is not an effective method for IPL analysis, most likely due to the high $\left(100{ }^{\circ} \mathrm{C}\right)$ temperature applied, leading to partial destruction of the IPLs, or to the use of diatomaceous earth to which part of the IPLs may have adsorbed. The error of the 'subtraction-method' was substantially higher than that of the separation method. In this method, IPL concentration is calculated by subtracting the CLGDGTs from total (IPL+CL) GDGTs, both of which are in general one order of magnitude higher than the IPL concentration. This leads to a lower significance for the measured values. Thus, even though the CL concentration can be measured relatively reproducibly (with relative standard deviation of 1-11\%), the error is relatively much larger for the small IPL concentration derived by subtraction. 


\subsection{Effect of extraction methods on distributions of IPL-crenarchaeol}

Two sediments from the Arabian Sea and the Icelandic shelf, and a microbial mat from Schiermonnikoog were directly analyzed for three crenarchaeol IPLs, i.e. MH-, DH- and HPH-crenarchaeol (Fig. 1b; cf. Pitcher et al., 2011b). The extraction yield of DH- and HPH-crenarchaeol was systematically significantly different between methods for the two sediments and the microbial mat (Fig. 3).

For all samples, HPH-crenarchaeol was clearly present in highest amount in the Bligh-Dyer extract, but at one
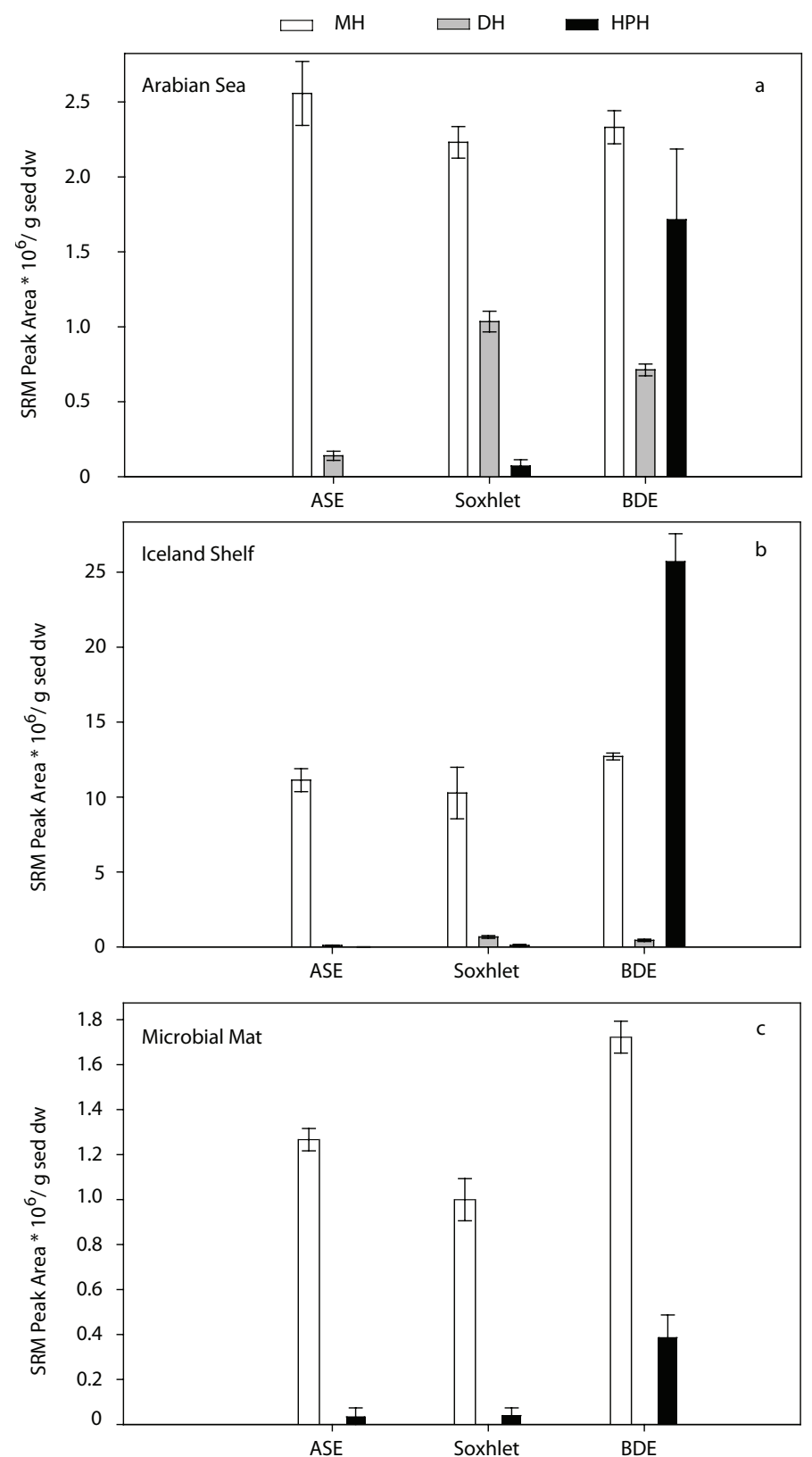

Figure 3. IPL crenarchaeol abundance (SRM peak area/ g sediment dry wt) directly analyzed with HPLC/ESI-MS² using different extraction methods for (a) Arabian Sea sediment, (b) Icelandic shelf sediment, (c) Schiermonnikoog microbial mat. Data presented are the means of triplicate extractions and duplicate analysis and error bars indicate \pm standard deviation $(\mathrm{MH}$, monohexose; $\mathrm{DH}$, dihexose; $\mathrm{HPH}$, hexose, phosphohexose). 
to four orders of magnitude lower concentration (microbial mat, Iceland shelf sediment) and not detectable in the ASE extract and two to three orders of magnitude lower in the Soxhlet extract of the Arabian Sea and Iceland sediments and the microbial mat. The highest recovery of HPH-crenarchaeol using Bligh-Dyer extraction is likely due to the higher temperatures at which the ASE and Soxhlet extraction were carried out (100 and 65 ${ }^{\circ} \mathrm{C}$, respectively), which caused degradation of the $\mathrm{HPH}$-crenarchaeol, in contrast to the room temperature of the Bligh-Dyer extraction. It is also possible that the HPH-crenarchaeol attached irreversibly to the surface of the diatomaceous earth used in ASE or the extraction thimbles used in Soxhlet extraction. Another reason for the superiority of the Bligh-Dyer method might be the use of a phosphate buffer, which increases the polarity of the extraction solvent and allows better dissolution of HPH-crenarchaeol (cf. White and Ringelberg, 1998).

Soxhlet extraction was slightly more efficient in extracting DH-crenarchaeol than Bligh-Dyer and ASE for both the Iceland shelf and the Arabian Sea sediments. The DH-crenarchaeol in microbial mats was below detection limit in microbial mat samples for all extraction methods. It had a yield for the ASE of only $10-20 \%$ of those of the Soxhlet and Bligh-Dyer extracts for the Arabian Sea and the Iceland Shelf sediment, while it was not detected at all in the microbial mat samples. This suggests that this IPL is also to some degree affected by high temperature, the diatomaceous earth and/or absence of a phosphate buffer.

The MH-crenarchaeol concentration in the Arabian Sea sediment was surprisingly unaffected by the extraction method as no significant differences were observed between the different treatments. However, it was present in slightly, but significantly, higher amount in the Bligh-Dyer than in the Soxhlet extract (but not the ASE extract) for the Iceland sediments, and both the Soxhlet and the ASE extracts for the microbial mat. It
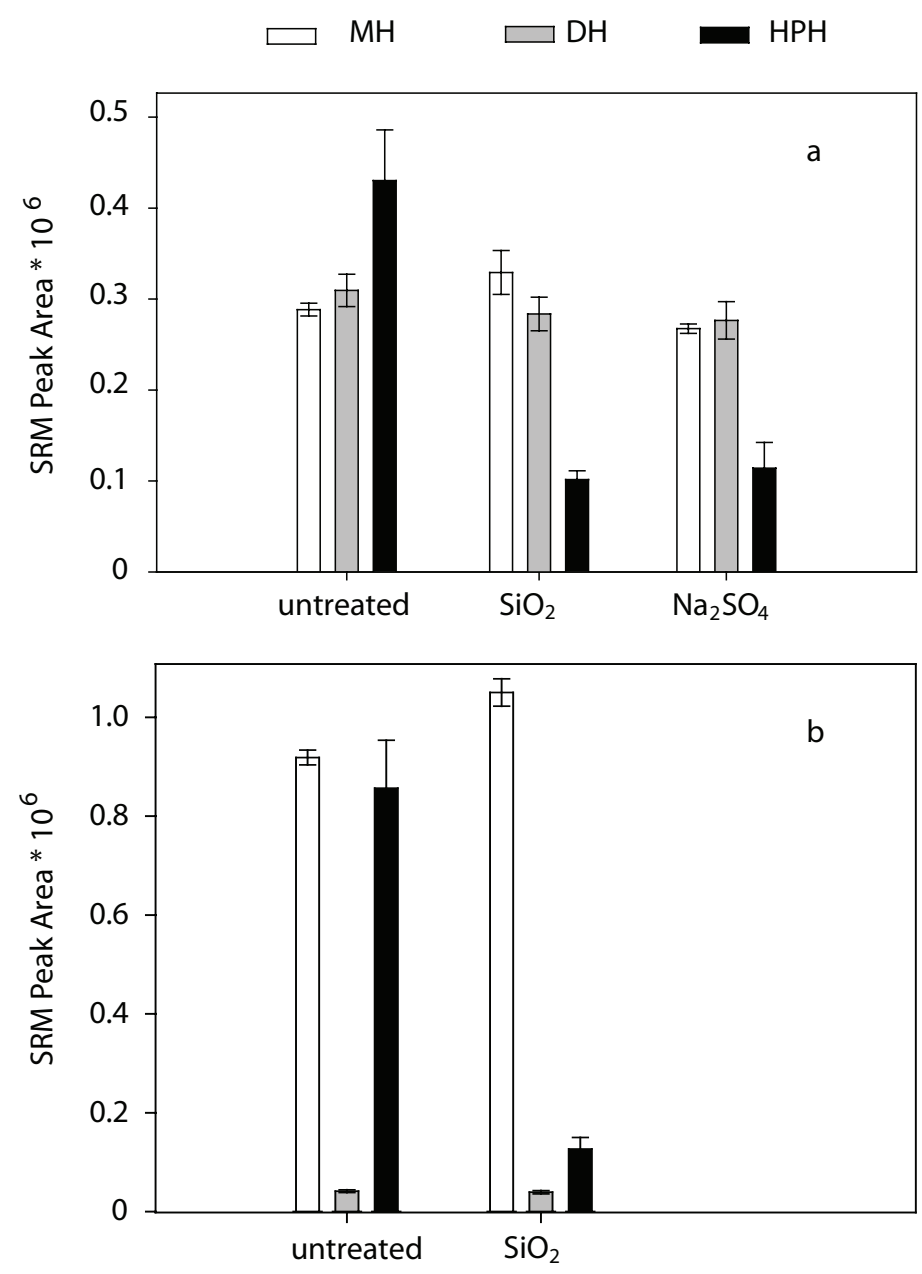

Figure 4. IPL crenarchaeol abundance (SRM peak area/aliquot) using different work up procedures with identical aliquots of a large combined Bligh-Dyer extract from (a) an Arabian Sea sediment and (b) an Icelandic shelf sediment (both different from the Bligh-Dyer extracts shown in Fig. 3); $\mathrm{SiO}_{2^{\prime}}$ IPL fraction of extract eluted from a silica column with $\mathrm{MeOH} ; \mathrm{Na}_{2} \mathrm{SO}_{4^{\prime}}$ extract dried over an $\mathrm{Na}_{2} \mathrm{SO}_{4}$ column. SRM areas represent peak response of identical aliquots injected. Data presented are the means of triplicate extractions and error bars indicate \pm standard deviation, with a single analysis for data in (a) and duplicate analysis for data in (b); $\mathrm{MH}$, monohexose; $\mathrm{DH}$, dihexose, $\mathrm{HPH}$, hexose, phosphohexose. 
is possible that the MH-crenarchaeol is thermally more stable than the other IPLs or that it was produced by degradation of the other IPLs (e.g. HPH-crenarchaeol and DH-crenarchaeol) with its concentration thereby increasing. However, it is also the least polar IPL and so may be extracted more readily with apolar solvent mixtures.

Thus, although the amount of IPL-derived GDGTs from Soxhlet and Bligh-Dyer extraction of sediments is similar (this study, Fig. 2; Huguet et al., 2010), Bligh-Dyer extraction is essential for determining the full suite of IPLGDGT head groups. This is particularly relevant as GDGTs with a phospho head group are predicted to

be more labile (Schouten et al., 2010) and so may be a more suitable marker for living Archaea.

\subsection{Effect of work-up procedures on IPL distribution}

Extracts are commonly filtered over $\mathrm{Na}_{2} \mathrm{SO}_{4}$ to remove traces of water and salt, especially when liquid/liquid extraction from an aqueous phase is involved. This procedure could also affect the distribution of IPLs. Furthermore, separation of IPLs over a $\mathrm{SiO}_{2}$ column could potentially lead to a bias in quantification of IPL-derived GDGTs if certain head groups adsorb selectively to silica or the glassware used (cf. Pitcher et al., 2009) or are even degraded during elution over silica. Elution of Bligh-Dyer extracts over a $\mathrm{Na}_{2} \mathrm{SO}_{4}$ or $\mathrm{SiO}_{2}$ column resulted in no significant changes for $\mathrm{DH}$-crenarchaeol, a slight increase for $\mathrm{MH}$-crenarchaeol and for $\mathrm{HPH}$-crenarchaeol a reduction by ca. $80 \%$ vs. the untreated extract for Arabian Sea sediment (Fig. 4a). For Iceland shelf sediment, the same was true. HPH-crenarchaeol was significantly reduced $(80 \%)$ after elution over a $\mathrm{SiO}_{2}$ column (Fig. 4b). Itprobably strongly adsorbs to $\mathrm{SiO}_{2}$ or $\mathrm{Na}_{2} \mathrm{SO}_{4}$, or the glassware, or is degraded during elution. The effect is likely much less for $\mathrm{DH}$ - and $\mathrm{MH}$-crenarchaeol as they possess the more stable glycosidic bonds and no charged head group. It is possible that some of the HPH-crenarchaeol is degraded to $\mathrm{MH}$-crenarchaeol, as the amount of latter also increased slightly but significantly after elution over the column. However, the MH-crenarchaeol signal could also have been enhanced by the removal of the matrix and a subsequent decrease in ion suppression during the measurement.

These results can be extrapolated to other GDGTs, as the head groups are likely to mainly determine the adsorption properties and chemical stability of IPL-GDGTs. Our results imply that drying should be achieved solely bwitha stream of $\mathrm{N}_{2}$, without drying agent. Furthermore, indirect IPL-GDGT quantification using $\mathrm{SiO}_{2}$ column separation will alsp introduce an error as a result of the HPH-GDGTs being lost on the $\mathrm{SiO}_{2}$ column.

The 'subtraction method' (Huguet et al., 2010a) as discussed above would avoid elution of IPL-GDGTs from a column and instead consist of hydrolyzing the complete extract and determining the IPLs as the difference of the total GDGTs and the CL-GDGTs (Huguet et al. 2010). However, as shown here, the method also introduces greater quantification error than for the $\mathrm{SiO}_{2}$ separation method (Fig. 2). Therefore, both methods have to be used with caution. The use of appropriate standards for direct quantification of IPL-GDGTs in the crude extracts can potentially resolve the dilemma of IPL-GDGT analysis.

\section{4}

\section{Conclusions}

ASE, Bligh-Dyer and Soxhlet extraction are all suitable extraction methods for analyzing CL-GDGTs. As shown previously, ASE is not an effective method for extracting IPL-GDGTs. Soxhlet and Bligh-Dyer extraction give similar yields, but the Soxhlet method showed a substantial bias for certain IPL-GDGTs, especially for HPH-GDGTs, which can be recovered mainly by way of Bligh-Dyer extraction. The latter method is therefore recommended for determining the full suite of IPL-GDGTs. 
Furthermore, no treatment should be applied to the extract as it will result in substantial loss of at least HPHGDGTs. Finally, quantification of IPL-GDGTs by subtracting the values before and after acid hydrolysis of the total lipid extract or by separation over a silica column gave similar results. However, problems with quantification errors and a bias due to the adsorption of phospholipids, respectively, suggests that both methods have to be applied with caution.

AcKNowledgements. The authors thank R. van Bommel for laboratory assistance and L. J. Stal, H. Fan and $\mathrm{N}$. Bale for providing the microbial mat sample, as well as the Master and crew of the R/V Pelagia and the participants of 64PE301 (PASOM) and 64PE341 (Long-chain diols). This is publication number DW-20111003 of the Darwin Center for Biogeosciences, which partially funded the project by providing a grant to S.S.

\section{REFERENCES}

Bauersachs, T., Speelman, E.N., Hopmans, E.C., Reichart, G.-J., Schouten, S., Sinninghe Damsté, J.S., 2010. Fossilized glycolipids reveal past oceanic N2 fixation by heterocystous cyanobacteria. Proceedings of the National Academy of Sciences of the USA 107, 19190-19194.

Biddle, J.F., Lipp, J.S., Lever, M.A., Lloyd, K.G., Sørensen, K.B., Anderson, R., Fredricks, H.F., Elvert, M., Kelly, T.J., Schrag, D.P., Sogin, M.L., Brenchley, J.E., Teske, A., House, C.H., Hinrichs, K.-U., 2006. Heterotrophic Archaea dominate sedimentary subsurface ecosystems off Peru. Proceedings of the National Academy of Sciences of the USA 103, 3846-3851.

Bligh, E.G., Dyer, W.J., 1959. A rapid method of total lipid extraction and purification. Canadian Journal of Biochemistry and Physiology 37, 911-917.

Boetius, A., Lochte, K., 2000. Regional variation of total microbial biomass in sediments of the deep Arabian Sea. Deep Sea Research Part II: Topical Studies in Oceanography 47, 149-168.

Bolhuis, H., Stal, L.J., 2011. Analysis of bacterial and archaeal diversity in coastal microbial mats using massive parallel 16S rRNA gene tag sequencing. ISME Journal 5, 1701-1712.

Brochier-Armanet, C., Boussau, B., Gribaldo, S., Forterre, P., 2008. Mesophilic crenarchaeota: proposal for a third archaeal phylum, the Thaumarchaeota. Nature Reviews Microbiology 6, 245-252.

De Rosa, M., Gambacorta, A., 1988. The lipids of archaebacteria. Progress in Lipid Research 27, 153-175.

DeLong, E.F., 1992. Archaea in coastal marine environments. Proceedings of the National Academy of Sciences of the USA 89, 5685-5689.

DeLong, E.F., King, L.L., Massana, R., Cittone, H., Murray, A., Schleper, C., Wakeham, S.G., 1998. Dibiphytanyl ether lipids in nonthermophilic Crenarchaeotes. Applied and Environmental Microbiology 64, 1133-1138.

Fuhrman, J.A., McCallum, K., Davies, A.A., 1992. Novel major archaebacterial group from marine plankton. Nature 356, 148-149.

Harvey, H.R., Fallon, R.D., Patton, J.S., 1986. The effect of organic matter and oxygen on the degradation of bacterial membrane lipids in marine sediments. Geochimica et Cosmochimica Acta 50, 795-804.

Huguet, C., Hopmans, E.C., Febo-Ayala, W., Thompson, D.H., Sinninghe Damsté, J.S., Schouten, S., 2006. An improved method to determine the absolute abundance of glycerol dibiphytanyl glycerol tetraether lipids. Organic Geochemistry 37, 1036-1041.

Huguet, C., Martens-Habbena, W., Urakawa, H., Stahl, D.A., Ingalls, A.E., 2010. Comparison of extraction methods for quantitative analysis of core and intact polar glycerol dialkyl glycerol tetraethers (GDGTs) in environmental samples. Limnology and Oceanography: Methods 8, 127-145. 
Karner, M.B., DeLong, E.F., Karl, D.M., 2001. Archaeal dominance in the mesopelagic zone of the Pacific Ocean. Nature 409, 507-510.

Koga, Y., Morii, H., 2005. Recent advances in structural research on ether lipids from Archaea including comparative and physiological aspects. Bioscience Biotechnology and Biochemistry 69, 2019-2034.

Koga, Y., Nishihara, M., Morii, H., Akagawa-Matsushita, M., 1993. Ether polar lipids of methanogenic bacteria: structures, comparative aspects, and biosyntheses. Microbiological Reviews 57, 164-182.

Lipp, J.S., Morono, Y., Inagaki, F., Hinrichs, K.-U., 2008. Significant contribution of Archaea to extant biomass in marine subsurface sediments. Nature 454, 991-994.

Liu, X., Lipp, J.S., Hinrichs, K.-U., 2011. Distribution of intact and core GDGTs in marine sediments. Organic Geochemistry 42, 368-375.

Logemann, J., Graue, J., Köster, J., Engelen, B., Rullkötter, J., Cypionka, H., 2011. A laboratory experiment of intact polar lipid degradation in sandy sediments. Biogeosciences 8, 2547-2560.

Macalady, J.L., Vestling, M.M., Baumler, D., Boekelheide, N., Kaspar, C.W., Banfield, J.F., 2004. Tetraether-linked membrane monolayers in Ferroplasma spp. a key to survival in acid. Extremophiles 8, 411-419.

Oba, M., Sakata, S., Tsunogai, U., 2006. Polar and neutral isopranyl glycerol ether lipids as biomarkers of Archaea in near-surface sediments from the Nankai. Organic Geochemistry 37, 1643-1654.

Pitcher, A., Hopmans, E.C., Schouten, S., Sinninghe Damsté, J.S., 2009. Separation of core and intact polar archaeal tetraether lipids using silica columns: Insights into living and fossil biomass contributions. Organic Geochemistry $\mathbf{4 0}$, $12-19$.

Pitcher, A., Rychlik, N., Hopmans, E.C., Spieck, E., Rijpstra, W.I.C., Ossebaar, J., Schouten, S., Wagner, M., Sinninghe Damsté, J.S., 2010. Crenarchaeol dominates the membrane lipids of Candidatus Nitrososphaera gargensis, a thermophilic Group I.1b Archaeon. ISME Journal 4, 542-552.

Pitcher, A., Hopmans, E.C., Villanueva, L., Reichart, G.-J., Schouten, S., Sinninghe Damsté, J.S., 2011. Niche segregation of ammonia-oxidizing Archaea and anammox bacteria in the Arabian Sea oxygen minimum zone. ISME Journal 5, 1896-1904.

Schleper, C., 2007. Diversity of uncultivated Archaea: perspectives from microbial ecology and metagenomics. In: Garrett, R.A., Klenk, H.P. (Eds.), Archaea: Evolution, Physiology, and Molecular Biology. Blackwell Publishing Ltd., Malden (MA), Oxford, Carlton, pp. 39-50.

Schouten, S., Hopmans, E.C., Pancost, R.D., Sinninghe Damsté, J.S., 2000. Widespread occurrence of structurally diverse tetraether membrane lipids: evidence for the ubiquitous presence of low-temperature relatives of hyperthermophiles. Proceedings of the National Academy of Sciences of the USA 97, 14421-14426.

Schouten, S., Hopmans, E.C., Schefuß, E., Sinninghe Damsté, J.S., 2002. Distributional variations in marine crenarchaeotal membrane lipids: a new tool for reconstructing ancient sea water temperatures? Earth and Planetary Science Letters 204, 265-274.

Schouten, S., Huguet, C., Hopmans, E.C., Kienhuis, M.V.M., Sinninghe Damsté, J.S., 2007. Analytical methodology for TEX86 paleothermometry by high-performance liquid chromatography/atmospheric pressure chemical ionizationmass spectrometry. Analytical Chemistry 79, 2940-2944.

Schouten, S., Hopmans, E.C., Baas, M., Boumann, H., Standfest, S., Könneke, M., Stahl, D.A., Sinninghe Damsté, J.S., 2008. Intact membrane lipids of "Candidatus Nitrosopumilus maritimus", a cultivated representative of the cosmopolitan mesophilic group I crenarchaeota. Applied and Environmental Microbiology 74, 2433-2440.

Schouten, S., Middelburg, J.J., Hopmans, E.C., Sinninghe Damsté, J.S., 2010. Fossilization and degradation of intact polar lipids in deep subsurface sediments: a theoretical approach. Geochimica et Cosmochimica Acta 74, 3806-3814.

Schubotz, F., Wakeham, S.G., Lipp, J.S., Fredricks, H.F., Hinrichs, K.-U., 2009. Detection of microbial biomass by intact polar membrane lipid analysis in the water column and surface sediments of the Black Sea. Environmental Microbiol- 
ogy 11, 2720-2734.

Sinninghe Damsté, J.S., Schouten, S., Hopmans, E.C., van Duin, A.C.T., Geenevasen, J.A.J., 2002. Crenarchaeol: the characteristic core glycerol dibiphytanyl glycerol tetraether membrane lipid of cosmopolitan pelagic crenarchaeota. Journal of Lipid Research 43, 1641-1651.

Spang, A., Hatzenpichler, R., Brochier-Armanet, C., Rattei, T., Tischler, P., Spieck, E., Streit, W., Stahl, D.A., Wagner, M., Schleper, C., 2010. Distinct gene set in two different lineages of ammonia-oxidizing Archaea supports the phylum Thaumarchaeota. Trends in Microbiology 18, 331-340.

Sturt, H.F., Summons, R.E., Smith, K., Elvert, M., Hinrichs, K.-U., 2004. Intact polar membrane lipids in prokaryotes and sediments deciphered by highperformance liquid chromatography/electrospray ionization multistage mass spectrometry - new biomarkers for biogeochemistry and microbial ecology. Rapid Communications in Mass Spectrometry 18, 617-628.

Van Mooy, B., Fredricks, H.F., Pedler, B.E., Dyhrman, S.T., Karl, D.M., Koblíz`ek, M., Lomas, M.W., Mincer, T.J., Moore, L.R., Moutin, T., Rappé, M.S., Webb, E.A., 2009. Phytoplankton in the ocean use non-phosphorous lipids in response to phosphorus scarcity. Nature 458, 69-72.

White, D.C., Ringelberg, D.B., 1998. Signature lipid biomarker analysis. In: Burlage, B.S. (Ed.), Techniques in Microbial Ecology. Oxford University Press, New York, pp. 255-259.

White, D.C., Davis, W.M., Nickels, J.S., King, J.D., Bobbie, R.J., 1979. Determination of the sedimentary microbial biomass by extractible lipid phosphate. Oecologia 40, 51-62.

White, D.C., Stair, J.O., Ringelberg, D.B., 1996. Quantitative comparisons of in situ microbial biodiversity by signature biomarker analysis. Journal of Industrial Microbiology 17, 185-196.

Zink, K.-G., Wilkes, H., Disko, U., Elvert, M., Horsfield, B., 2003. Intact phospholipids - microbial "life markers" in marine deep subsurface sediments. Organic Geochemistry 34, 755-769. 